\title{
Representações de Macau após a Guerra do Ópio no Poema "Militar" The Fair Chinese Maid; a Tale of Macao [1842]
}

\author{
Rogério Miguel Puga \\ NOVA-FCSH/CETAPS
}

O poema anónimo The Fair Chinese Maid; a Tale of Macao, in Rhyme (1842), da autoria de um soldado britânico ("An officer in China") faz parte da longa lista de obras literárias sobre Macau produzidas por militares europeus, no âmbito de serviço militar e/ou colonial, especialmente durante e após a Guerra do Ópio, ${ }^{1}$ conflito que estimulou o interesse dos britânicos pela China. O texto, considerado por Shaw (62) um dos primeiros poemas anglófonos redigidos em Hong Kong, é publicitado no jornal The Spectator de 29 de Outubro de 1842 (1056), que, na página 1050, se refere ao espírito da obra como "bryronic":

a poem begun by an English officer to "while away a tedious fortnight in the harbour of Hong-Kong"; and only the first canto finished, because professional duty calls him elsewhere. Nothing in the poem is attributed to the Chinese but on authority, he tells us; which may be as regards forms, but the spirit of the thing is Byronic.

1. Citamos, a título de exemplo, a obra de John Elliot Bingham, Narrative of the Expedition to China: From the Commencement of the War to its Termination in 1842; with Sketches of the Manners and Customs of that Singular and Hitherto almost Unknown Country, publicada em 1843. 
The Fair Chinese Maid é ainda anunciado quer no Literary Gazette de 5 de Novembro de 1842 (768), como um "new poem", quer no The Athenaeum de 5 de Novembro desse ano (958), publicação que, em 7 de Janeiro de 1843 (The Athenaeum 14), acaba por criticar o poema e aconselhar o seu autor a não redigir mais nenhum canto:

The Fair Chinese Maid; a Tale of Macao, by an Officer in China-This first canto of a poem was written, its author states, to beguile an idle fortnight on shipboard; and under such circumstances, perhaps no more need be said about it. Idleness is the avowed parent of many a folly; and may be admitted to take the blame of this among the rest. The author laments that a return to active life prevented his earning the matter beyond the first canto; but promises a second, in case the English public shall express any great anxiety for it. Our advice to him, on their behalf, is, that if he can find any other occupation for his time, to think no more about the Chinese Maid.

A estrutura da obra em questão, dividida em 146 estâncias que constituem o primeiro "canto", aproxima-a da epopeia, pois, como veremos, um dos objectivos do poema é quer elogiar os feitos imperiais (militares e comerciais) britânicos no delta do rio das Pérolas, nomeadamente a determinação dos agentes coloniais, quer dar a conhecer à metrópole os futuros súbditos da rainha Vitória em Hong Kong. Obviamente, o local no delta mais óbvio para a acção do romance seria, na altura, a Macau portuguesa, lar dos britânicos na China desde 1700, e onde houve muitas relações amorosas como as ficcionalizadas no poema narrativo.

O oficial anónimo encontra-se, por obrigação profissional, num barco no porto de Hong Kong e afirma que foge à realidade da "guerra" através da escrita-imaginação, rumo aos "prazeres" da "ficção" (iii; nossa tradução). O primeiro canto do poema foi redigido após o regresso de uma breve visita a Macau, durante a qual o autor decidiu localizar a acção da obra na urbe luso-chinesa, onde os estrangeiros gozavam de uma liberdade quase total e mantinham, de facto, amantes chinesas. O labor militar e diplomata impede o oficial de redigir logo o segundo canto, e, tanto quanto sabemos, nunca o terá chegado a redigir, ou, pelo menos, nunca o publicou. O referido elemento paratextual contempla ainda o horizonte de expectativas do 
público-alvo britânico implicado pelo autor, que, ao escrever da periferia do império em formação para a metrópole, afirma:

\begin{abstract}
To the mass at home, to whom Chinese histories and customs are novel things, even this one canto may give an outline of information, perhaps not unmingled with amusement, nor wholly devoid of interest. Nothing is therein told of, or attributed to, the Chinese, for which a respectable authority could not be given. The author, however, has had no time to make notes. (iv)
\end{abstract}

É notória a preocupação didáctica, sobretudo devido à referência às notas explicativas que deveriam acompanhar o texto, que o autor afirma valorizar tanto quanto os chineses valorizam os seus rabichos, num exercício de comparação intercultural que o caracteriza e valida como um autor informado. Face à Guerra do Ópio e à "conquista" de Hong Kong, tornava-se urgente narrar e mitificar essas façanhas coloniais também através da ficção, familiarizando, no processo, os britânicos "em casa" com os novos súbditos de sua majestade britânica no delta do rio das Pérolas através do processo a que Leask (1998: 168) chama "objectividade imperialista". Aliás, desde a falhada embaixada de Lord Macartney (1793) que a imagem da China mudara na Grã-Bretanha e na Europa, tornando-se mais negativa para legitimar e intensificar a (retórica da) necessidade de forçar o Império do Meio a modernizar-se, a "civilizar-se". (Forman: 59; Wagner: 23; Kerr e Kuehn: 4) Não são, portanto, ingénuas as referências do autor-soldado ao local e ao contexto da escrita, bem como à necessidade de se deslocar mais a Norte, na China, para continuar a construir o império, através das "armas" e das "letras", um antigo tópico colonial, como demonstra a expressão da épica de Camões, "Numa mão sempre a espada, e noutra a pena". (VIII, 79) A figura do soldado (agente) colonial a narrar o processo em que participava era já frequente e continuaria a sê-lo na Grã-Bretanha, bastando recordar, por exemplo, Richard Francis Burton (1821-1890), Rudyard Kipling (1965-1936), ou o marinheiro Joseph Conrad (1857-1924).

O poema assume-se, portanto, como alegoria do poder colonial britânico, e a despedida do mercador ou soldado que deve voltar a casa no final da missão torna-se um dever nacional, sendo essa determinação e esse labor essenciais no âmbito do projecto de construção 
do império britânico. O texto representa quer a relação amorosa entre um oficial britânico e uma jovem chinesa em Macau até à hora da partida daquele, quer alguns costumes sínicos, como o abandono de bebés do sexo feminino. Aliás, essa temática é referida, desde cedo, por inúmeros viajantes portugueses e anglófonos ao visitar a China, ${ }^{2} \mathrm{e}$ é ficcionalizada em romances como City of Broken Promises (1967), de Austin Coates, cuja Bildungsheldin é vítima dessa mesma prática. (Puga, A World of Euphemism: 403-407) Também a protagonista do poema é abandonada quer à nascença pelos progenitores quer, posteriormente, já adulta (exoticizada de forma orientalista), pelo homem europeu. A cultura chinesa, de uma forma geral, não conferia tanto valor à rapariga (filha) quanto ao rapaz (filho), uma vez que apenas este poderia prestar culto aos seus antepassados e não partia do seu lar para se inserir na família da noiva quando atingia a idade de começar a trabalhar na terra. (Eastman: 15-45) No início do poema inacabado, o narrador autocaracteriza humildemente o seu poema como uma "careless, desultory song/Hard", (2) antes de apresentar Edmund e contextualizar a acção, delimitando o espaço veranil de Macau, que se estende até às Portas do Cerco, fronteira com a chamada "China profunda":

(...) beyond the gate

of that old Christian settlement, Macao,

Where a long while the Lusitanian state

Held timid sway, - though far more valiant now,

Since first was heard the British cannon's roar,

Announcing death on Han's celestial shore;

Beyond the gate - the long established limits

Of western, ruthless, proud barbarian sway; (...)

Walked a young English sailor, blithe and free,

Who ne'er before had crossed the China sea. (3)

2. Sobre o abandono de bebés do sexo feminino em Macau até ao século XX, veja-se Watts (1997: 7188). As bebés indesejadas são vendidas, afogadas ou abandonadas à nascença, junto de instituições religiosas e posteriormente adoptadas, como acontece no poema de que nos ocupamos. Esta prática é referida logo nos primeiros escritos portugueses sobre a China, nomeadamente por Gaspar da Cruz, na sua obra de 1569, "Cousas da China e do Reino de Ormuz". (Cruz, 1989: 114) Sobre o infanticídio entre os chineses, veja-se ainda Doolittle. (203-209) 
O passado e o presente históricos são convocados logo no início da obra, enquanto a repetição da referência à fronteira das Portas do Cerco acentua a pequenez e os limites da cidade incrustada na China, império que recentemente encarara as "bestas" e os canhões ocidentais (britânicos), tornando-se óbvio o imaginário bélico a marcar, desde cedo, o espaço do delta do rio das Pérolas e até o estabelecimento português onde decorre a acção, e que, desde 1700, acolhe os ingleses no delta do rio das Pérolas. Curioso é o recurso ao adjectivo "timid" para caracterizar a administração lusa em Macau, podendo ser uma crítica à neutralidade do território durante a então recente Guerra do Ópio. No entanto, como é sabido, a neutralidade foi apenas aparente, pois os portugueses em Macau, cientes da sua necessidade de sobrevivência no Sul da China, agradam sobretudo às autoridades chinesas, mesmo declarando a sua suposta neutralidade face à velha aliada europeia. (Dias: 1993) Edmund, um jovem mercador britânico na China, qual flâneur, usufrui da liberdade que o território católico de Macau lhe permite, e para as autoridades chinesas é, de facto, esse o grande valor da cidade co-administrada pelos portugueses, pois permite ao mandarinato usufruir dos lucros e benefícios do comércio com os estrangeiros que residem na Macau estrangeira (murada, e logo, fora da China) e são "administrados" pelos portugueses. (Puga, A Presença Inglesa: 99-102) Aliás, pouco depois da publicação da obra, chegaria a Macau um dos seus mais polémicos governadores, Ferreira do Amaral (1803-1849), que aproximaria Macau de uma colónia mais típica do século XIX, ao reivindicar uma série de direitos para a urbe e reforçar a autonomia e o poder lusos faces ao mandarinato. (Silva, 2002) Se atentarmos no contexto em que o autor militar se deslocara à China e permanecera também em Macau, na sequência da Guerra do Ópio, entendemos facilmente a referência ao passeio calmo que a Macau "neutral" permite. Aliás, no âmbito do referido conflito bélico sino-britânico dá-se, por exemplo, em Agosto de 1840, a chamada Batalha da "Barrier Gate" (das Portas do Cerco), episódio em que corvetas inglesas atacam soldados, artilharia e juncos sínicos nas imediações (chinesas) do istmo que liga Macau à China "profunda", com a desculpa de (supostamente) defender a cidade contra ataques chineses, (Hanes e Sanello: 108) atitude que desagrada às autoridade de Macau. Ou seja, o espaço da acção do poema também 
é influenciado e marcado pela história e pela memória e vivência militar britânicas no território em questão, que foi o lar dos ingleses na China até à fundação de Hong Kong.

O narrador descreve Macau como um espaço de influência e administração portuguesas, pois os ingleses "at Canton dwelt", (3) "deixando" as mulheres no enclave europeu, o que, de facto, se passava, pois, como o poema informa, as mulheres estrangeiras - "whether wives or daughters" (3) - estavam proibidas de entrar na China, mesmo no complexo de feitorias de Cantão, ou seja, Macau é representado como o espaço feminino do antigo "Canton trade", contexto que mudaria com o final da Guerra do Ópio e da consequente assinatura do Tratado de Nanquim (29-08-1842), que, no ano da publicação do poema, abre cinco portos chineses ao comércio livre com o Ocidente e oficializa a fundação da colónia de Hong Kong. Efectivamente, apenas após a referida guerra as mulheres passam a poder visitar e pernoitar em Cantão e nos outros portos abertos ao trato estrangeiro, como revela o diário de Rebecca Kinsman. (397) Nos anos quarenta do século XIX, Rebecca já usufrui de uma maior liberdade de movimento em Cantão, por comparação, por exemplo, à que Harriet Low gozara em Novembro de 1830, quando a sua subida até Cantão, escondida num barco, levara os chineses a parar o comércio até que a jovem e a sua tia regressassem a Macau. (Low: 190-194) ${ }^{3}$ O enclave luso-chinês torna-se, assim, o espaço feminino do comércio do Old China Trade, onde essas famílias norte-americanas e europeias permanecem todo o ano, mesmo depois da abertura dos portos chineses ao comércio, e onde missivas e diários são redigidos, por vezes, em solidão, durante a estação comercial (meses de Outono e Inverno), por mães de família enquanto os maridos se encontram na feitoria de Cantão.

A ida ao Norte da China que o autor refere na introdução implica a diplomacia e os interesses britânicos na China, sendo, portanto, significativa. O delta do rio das Pérolas é, assim, um universo marcado também pelas imposições relacionadas com o género (gender), tal como acontecia no resto do mundo; no entanto, aqui acontecia

3. Essa maior liberdade em Cantão é descrita, por exemplo, pelo autor-viajante (não residente) norte-americano Osmond Tiffany na obra The Canton Chinese (1849). 
por imposição chinesa, sendo tal realidade filtrada e focalizada pelo militar britânico, que, enquanto agente colonial, ficcionaliza uma história de amor "colonial", cujo protagonista regressa para o lar europeu, abandonando a amada num território do império português, assim representado como local também feminino, mas que nunca substitui a metrópole. É um espaço sobretudo de missão e de dever colonial. Aliás, a censura, a rejeição, o controlo e o "medo" do colonizador britânico do século XIX face ao modus vivendi do "nativo" são veiculados através da conhecida expressão idiomática "(s)he's going native". The Chinese Maid convoca e rentabiliza didacticamente a retórica daquilo a que poderíamos chamar poética (ideológica) colonial, que, por sua vez, descreve o soldado/mercador que regressa a casa como exemplo, bem como a sedutora e até perigosa mulher "nativa" quer como influência negativa, no caso da primeira mulher que Edmund segue rumo à China, quer como vítima (forçosa e naturalmente abandonada) do plano imperial britânico, no caso, a europeizada Kathleen. O poema veicula, assim, também as ansiedades e os estereótipos coloniais de então, também através dos exercícios quer da exoticização (Leask, 1992, 1998) do Outro chinês, quer da justificação da guerra contra a China. (Shaw: 63) Já a mulher europeia, como afirmámos anteriormente, está proibida de entrar na China, tentando o narrador adivinhar o motivo para tal proibição: "in [Chinese] fear/Barbarian dames might colonize the land;/ Or else they feared a prophecy well known,/That a fair dame should Heaven's son dethrone", (3) enquanto estabelece um paralelismo colonial entre a profecia que é fruto da superstição chinesa e o poder da rainha da Grã-Bretanha, que acabara de derrotar o imperador. Ou seja, mesmo as relações amorosas e a presença feminina na China colonizada (Hong Kong e Macau) são encaradas do ponto de vista colonial, como não poderia deixar de ser.

O protagonista Edmund - apresentado como um jovem inconsciente que persegue "two small feet" (4) - percorre as ruas da urbe sem encontrar qualquer jovem nativa, pois todas as raparigas "honestas" estão fechadas em casa, "much like a captive bird (...) on formless feet (...) tiny feet (...) funny sight (...) twinklers shinning 
bright".(4) $)^{4}$ Surge, de repente, uma misteriosa mulher chinesa de pés enfaixados, que é descrita através da adjectivação cumulativa e que fazia já parte da imaginação cultural britânica, e despertaria o interesse do leitor europeu. Edmund persegue a chinesa de pés enfaixados até à China, atravessando as Portas do Cerco, sem saber que ultrapassar "the barrier gate was deemed a sort of treason". (4) A jovem, aos olhos do mercador, não é mais do que os seus pés deformados até se virar e lhe chamar, antes de desaparecer, "Fankwei", (4) ou seja, diabo estrangeiro. Aliás, o narrador revela, mais adiante, duas vezes, o significado da expressão negativa chinesa: "foreign devil". $(6,7)$ De seguida, o jovem estrangeiro é espancado por um grupo de chineses por se encontrar em território sínico, tornando-se a chinesa exoticizada símbolo de perigosa sedução, por oposição à chinesa europeizada pelo padre Dillon, por quem é seguro Edmund apaixonar-se. A voz feminina do Outro recém-inimigo ofende, assim, o protagonista, antes de quatro personagens masculinas chinesas o assaltarem, tornando-se evidente o campo semântico negativo que marca as relações sino-britânicas na altura, sobretudo em território chinês, do ponto de vista quer dos estrangeiros, quer dos súbditos do imperador: "But being English he despised them all,/The shaven long-tailed of Heaven's son". (5) Não será, portanto, de estranhar que a descrição do conflito físico se arraste durante várias estâncias. Ao ser atacado, Edmund - "Albion (...) our hero" (7) - foge da China "profunda" para a segurança das Portas do Cerco, perseguido por mais chineses que reforçam o bando inicial, enquanto o "Lusitanian sentry" (7) que guarda a fronteira entre Macau e a China profunda é apresentado a honrar o herói britânico, unindo-se assim os interesses e até ódios das duas nações europeias com "colónias" permanentes no Império do Meio. Para além do lar do padre Dillon, onde o jovem protagonista recupera, decerto na zona da Macau cristã, onde também o casal mais tarde se despede (Praia Grande), as Portas do Cerco - abertas na muralha norte transversal, no estreito istmo que separa Macau da China - funcionam como fronteira erguida, logo em 1573, pelas autoridades chinesas. O mandarinato fechou estrate-

4. De acordo com Machado, "As mulheres de distinção [em Macau] vivem isoladas: nunca se expõem a serem vistas pelos homens. (...) A mulher sai à rua duas vezes por ano, para visitar seus parentes". (1926: 23) 
gicamente o istmo e transformou Macau numa "ilha" administrativa, que seria facilmente controlada, pois cada vez que os portugueses desobedecessem ao mandarinato a referida porta seria encerrada e Macau não conseguiria arranjar comida, nem empregados; daí que a administração portuguesa nunca tenha tido total controlo sobre o território. Nas referidas Portas se situava, do lado português, um posto de polícia, a "sentinela" referido pelo poema.

Além Portas do Cerco - já em território chinês proibido aos estrangeiros, sobretudo após a derrota (da Guerra do Ópio) que exaltara os ânimos dos chineses -, o agressor colonial britânico (individualizado em Edmund) perde a segurança que Macau lhe confere e é agredido por chineses. Aliás, as lutas entre oficiais ingleses e a população chinesa quando os primeiros atravessam as Portas do Cerco, em passeio, e entram em território chinês são comuns ao longo dos séculos XVIII-XIX, como se pode verificar através das fontes históricas de Macau. ${ }^{5} \mathrm{O}$ jovem ferido é recolhido pelo padre irlandês ("padre (...) Dillon": 8) e apaixona-se pela sua cuidadora Kathleen, a exoticizada jovem chinesa que o acompanha até ao momento da partida, que se dá após um romântico e solitário passeio pela Praia Grande: "To leave Macao - He bowed to stubborn fate;/But when he told poor Kathleen he must sail,/To paint her grief what language can avail?". (34) Relativamente aos romances interétnicos e ao forçoso regresso do homem europeu a casa, estabelece-se um interessante diálogo intertextual entre obras de língua inglesa e portuguesa sobre Macau, nomeadamente no que diz também respeito à paisagem antropológica, natural e arquitectónica, espaço de relações amorosas entre oficiais europeus e mulheres chinesas que, na maioria das vezes, são abandonadas. Kathleen fora abandonada pelos pais e o padre Dillon salvara a bebé, resgatando as suas vida e alma, como ela confessa ao mercador. O tutor teme o sofrimento da jovem e tenta protegê-la do visitante, que, como todos os outros, acabaria por partir de Macau, sendo, portanto, o abandono descrito no poema idêntico ao que as mulheres chinesas têm como certo em romances como City of Broken Promises. Na literatura portuguesa também

5. Consultem-se, por exemplo, as chapas do procurador do Senado para o mandarim da Casa Branca, em 1816 e 1822, publicadas por Ping e Zhiliang ed. (vol. 5, doc. 148; vol. 6, doc. 40). 
encontramos paralelismos intertextuais com o poema anónimo, nomeadamente em relação à vivência do género feminino, metaforizado na cabaia envergada pela mulher nativa, face à sociedade patriarcal. Para além do conto "A-Chan, A Tancareira" (1950), de Henrique de Senna Fernandes, (1997: 18-19) e do romance Histórias de Macau (1987), de Altino do Tojal, (1998: 7) nos quais os oficiais e funcionários públicos portugueses abandonam mulheres chinesas ao regressar à Europa, na antologia publicada, em 1956, por Deolinda Conceição, Cheong-Sam: A Cabaia, (1995, 13-21, 23-26, 27-29, 31-35, 43-49, 55-57) o conto "Cheong Sam" representa o homicídio de uma mulher pelo marido que deseja defender a honra, mesmo quando a violação sexual da primeira resulta do abandono por parte dele. No conto "Calvário de Lin Fong" um europeu que prometeu levar a amante chinesa para a Europa abandona-a grávida, quando lhe fez vislumbrar uma vida melhor, e "A Esmola" ganha forma e sentido a partir de temas como a miscigenação, a vida cultural dupla e o casamento interétnico em Macau. Já "Arroz e Lágrimas" ficcionaliza a miséria da mulher oriental, enquanto "O Romance de Sam-Lei" é um conto de formação que traça o percurso de uma jovem sínica pela sua relação amorosa e a segurança conseguida através do matrimónio. Nos contos "Aquela Mulher" e "Os Sapatinhos Bordados de Anui" marcam presença temas como a adopção, a miséria feminina, a venda de filhas e a valorização do filho varão, também presentes em The Chinese Maid.

Kathleen é apresentada como detentora de uma beleza ímpar adornada por vestes chinesas e pés pequenos, (9-10) que o narrador compara aos das "Western dames", antes de se referir ao aprisionamento das mulheres chinesas através dos pés enfaixados e de concluir, dramaticamente através de uma interjeição depreciativa que assenta em estereótipos físicos: "Oh, monstruous land! My patience nearly fails,/With thy crook'd, bandaged feet, and ape-like tails". (10) A atenção do narrador "racista" (Shaw: 66) e do protagonista detém-se sobretudo na "fair one", (11) o elemento feminino exoticizado, e essa estratégia serve o propósito de criticar a crueldade que parece marcar essa sociedade, sendo os rabichos dos chineses também ridicularizados, numa curta digressão, antes de estes serem descritos como altamente conservadores e resistentes à mudança, sobretudo à conversão religiosa por parte de missionários jesuítas. (16) Macau é 
também descrita como centro de missionação europeia no Oriente, e o padre Dillon é apresentado como honesto, afável e fluente em cantonense, (17-19) imagem que se afasta da caracterização negativa de religiosos católicos na literatura protestante britânica. O próprio narrador chega a dirigir-se ao leitor para reforçar e validar essa caracterização positiva: "I know to some the thought will be distressing: " - /An Irish Jesuit good? Be quiet, fool!/My one exception only proves your rule." (20) Aliás, como já afirmámos, a Macau lusa é descrita como um espaço católico logo no início do poema e é várias vezes apresentada como centro missionário de conversão de chineses ao catolicismo. $(16,21)$ É nesse contexto religioso que o jesuíta Dillon viajara para Macau e posteriormente acolhera Kathleen, possibilitando-lhe uma educação europeia, na segurança do seu lar, onde a jovem também aprendera história da China, referência que dá lugar a uma longa digressão sobre cultura, história e medicina tradicional chinesas, (28-33) terminando o poema com uma breve nota cómica (e comparação intercultural) em torno do papel (que não é, afinal, feito) de arroz chinês que Kathleen usa para escrever a Edmund: "I'm afraid-/I hoped to see the works of Byron, Babbage,/Et cet'ra, - printed upon greens, or - cabbage". (41)

Já a jovem chinesa descreve os britânicos como "fair haired race", (11) com quem ela há muito desejava interagir, revelando a sedução que Edmund exercera à partida sobre ela. $\mathrm{O}$ jovem estranha o nome irlandês da sua cuidadora chinesa e várias afirmações do narrador denunciam a relação entre nomes próprios, língua, religião e identidade nacional e estrangeira, $(13-16,20-21,27)$ sobretudo no que diz respeito à identidade irlandesa (e religiosa) do padre Dillon, o Outro católico, e, portanto, o "definitional other ${ }^{\prime \prime}$ face à identidade britânica ("Britishness"). O jesuíta, que planeara casar Kathleen com um chinês cristão, e a ama portuguesa da jovem avisam-na da possibilidade de o inglês protestante a magoar ao regressar a casa, mas o casal apaixona-se, como não poderia deixar de ser, e o narrador reflecte longamente sobre a rivalidade entre católicos e protestantes (15-16) e descreve os passeios e o vestuário do padre jesuíta que se passeia

6. Sobre o papel do anticatolicismo na formação da identidade nacional inglesa, vejam-se Colley (1992) 309-329, Marotti (1999), Marotti (2005), Shell (2006), Shell (2007), Corens (2011) 441-459 e Àlvarez-Recio (2011). 
pela "Praya Grande [or] Lusitanian beach", (21) convocando assim a toponímia da urbe, nomeadamente a estrada marginal que era percorrida e habitada sobretudo por estrangeiros em Macau, (34) por entre "hills, mid rocks and billows" (21) que caracterizam o espaço da acção, onde, de acordo com o narrador, não existiam placas com nomes das ruas. Na última noite em que Edmund está em Macau, o casal despede-se a passear também na Praia Grande (34):

They pass the verdant sward that spreads before
The handsome flight of steps, which you ascend
To San Francisco's church - close to the shore.
They hear soft music with the zephyrs blend:
While Portugal's gay colonists were seen
Dancing all joyous on the moon-lit green.
(...)
The walls were hills - the sea and purple islands, -
With the fair silent town's moon-glitt'ring piles. (34)

A descrição e a enumeração de diversos elementos dos espaços natural e arquitectónico, bem como a paisagem acústica ou sonora e a felicidade de foliões portugueses acentuam a solidão do casal momentos antes da separação. São ainda, mais uma vez, apresentados chineses (estereotipados) de rabicho a fumar junto a rochedos, bem como os montes de Macau e as fortalezas - o fortim de São Pedro (1622), a fortaleza de São Francisco (c.1623), a fortaleza de Nossa Senhora do Bom Parto (c.1622) e a fortaleza de São Tiago da Barra (c.1622) - construídas, sobretudo após o ataque holandês de 1622, no litoral para defender o porto: "Tis formidable when seen/By night". (35) O destaque conferido a estas construções militares não será de admirar se atentarmos na profissão do autor-soldado do poema. A sedução e o romance temporários entre o britânico e a jovem chinesa, abandonada pelos seus progenitores chineses e educada pelo padre católico, também ele uma figura patriarcal europeia, funcionam metonimicamente como metáfora para a relação imaginária (de protecção e de educação) entre os agentes coloniais europeus e os chineses que se 'europeizassem', ecoando intertextualmente a famosa expressão "white man's burden", que Rudyard Kipling viria a cunhar, em 1899, no seu poema "The White Man's Burden: The United States and the Philippine Islands". 
O poema de que nos ocupámos torna-se, assim, também uma ferramenta literária e cultural que concorre para a construção da narrativa imperial através de símbolos culturais sínicos estereotipados, como o rabicho dos homens chineses, os pés enfaixados de algumas mulheres e as diversas paisagens (sobretudo militares) de Macau, entreposto comercial, religioso, cultural e militar português que os britânicos utilizam como o seu lar na China desde 1700 e que, portanto, se assume como o espaço de acção mais realista para o enredo amoroso e político de The Chinese Maid, publicado anonimamente, em Londres, no ano em que termina a Guerra do Ópio.

\section{Obras Citadas}

Anónimo. The Fair Chinese Maid; Tale of Macao, in Rhyme, by an Officer in China. Londres: Joseph Thomas, 1842.

Àlvarez-Recio, L. Fighting the Anti-Christ: A Cultural History of Anti-Catholicism in Tudor England. Brighton: Sussex Academic Press, 2011.

The Athenaeum: Journal of English and Foreign Literature, Science, and the Fine Arts 784, 5-11-1842; 793, 07-01-1843.

Bingham, John Elliot. Narrative of the Expedition to China: From the Commencement of the War to its Termination in 1842; With Sketches of the Manners and Customs of that Singular and Hitherto almost Unknown Country. Londres: Hnery Colburn, 1843.

Camões, Luís Vaz de. Os Lusíadas. Ed. Emanuel Paulo Ramos. Porto: Porto Editora, 1992.

Colley, L. "Britishness and Otherness: An Argument": Journal of British Studies 31 (1992): 309-329.

Conceição, Deolinda da. Cheong-Sam: A Cabaia. Macau: Instituto Cultural de Macau-Instituto Português do Oriente, 1995.

Corens, L. "Catholic Nuns and English Identities. English Protestant Travellers on the English Convents in the Low Countries, 1660-1730." Recusant History 30:3 (2011): 441-459.

Cruz, Gaspar da. "Cousas da China e do Reino de Ormuz". Primeiros Escritos Portugueses sobre a China. Ed. Luís de Albuquerque. Lisboa: Publicações Alfa, 1989. 51-181.

Dias, Alfredo Gomes. Macau e a I Guerra do Ópio. Lisboa: Instituto Português do Oriente, 1993.

Doolittle, Justus. Social Life of the Chinese with Some Account of Their Religious, Governmental, Educational, and Business Customs and Opinions. With Special but not Exclusive Reference to Fuhchau 2. Nova Iorque: Harper \& Brothers, 1865. 


\section{REAP/JAPS 26}

Eastman, Lloyd E. Family, Fields and Ancestors: Constancy and Change in China's Social and Economic History-1550-1949. Oxford: Oxford University Press, 1988.

Fernandes, Henrique de Senna. Nam Van: Contos de Macau. Macau: Instituto Cultural de Macau, 1997.

Forman, Ross, G. China and the Victorian Imagination: Empires Entwined. Cambridge: Cambridge University Press, 2013.

Hanes, W. Travis e Frank Sanello. The Opium Wars. Naperville: Sourcebook, 2002.

Kerr, Douglas e Julia Kuehn. "Introduction." A Century of Travels in China: Critical Essays on Travel Writing from the 1840s to the 1940s. Ed. Douglas Kerr e Julia Kuehn. Hong Kong: Hong Kong University Press, 2007. 1-11.

Kinsman, Rebecca C. "The Daily Life of Mrs. Nathaniel Kinsman in China." The Essex Institute Historical Collection LXXXVII (Outubro 1951): 388-409.

Leask, Nigel. British Romantic Writers and the East: Anxieties of Empire. Cambridge: Cambridge University Press, 1992.

---. "'Wandering Through Eblis': Absorption and Containment in Romantic Exoticism". Romanticism and Colonialism: Writing and Empire, 1780-1830. Ed.Tim Fulford e Peter J. Kitson. Cambridge: Cambridge University Press, 1998. 165-88.

Literary Gazette and Journal of the Belles Lettres, Arts, Sciences 1346, 05-11-1842.

Low, Harriett. Lights and Shadows of a Macao Life: The Journal of Harriett Low, Travelling Spinster (1829-1834). Ed. Nan P. Hodges e Arthur W. Hummel. Woodinville: The History Bank, 2002.

Machado, Carlos Jacinto. A China e os Chineses. Macau: Editora Padre José da Silva Lucas, 1926.

Marotti, A. F. (ed.) Catholicism and Anti-Catholicism in Early Modern English Texts. Houndmills: Macmillan, 1999.

Marotti, A. F. Religious Ideology and Cultural Fantasy: Catholic and Anti-Catholic Discourses in Early Modern England. South Bend: University of Notre Dame, 2005.

Ping, Jin Guo e Wu Zhiliang (ed.) Correspondência Oficial Trocada entre as Autoridades de Cantão e os Procuradores do Senado: Fundo das Chapas Sínicas em Português (1749-1847). Macau: Fundação Macau, 2000.

Puga, Rogério Miguel. A World of Euphemism: Representações de Macau na Obra de Austin Coates: City of Broken Promises enquanto Romance Histórico e Bildungsroman Feminino. Lisboa: Fundação para a Ciência e a Tecnologia-Ministério da Ciência, Tecnologia e Ensino Superior/Fundação Calouste Gulbenkian, 2009.

---. A Presença Inglesa e as Relações Anglo-Portuguesas em Macau (1635-1793). Lisboa: CHAM/Centro Cultural e Científico de Macau, 2009.

Shaw, Damian. "The Fair Chinese Maid; A Tale of Macao. Or, the First English Poetry of Hong Kong?." New Zealand Journal of Asian Studies 16:1 (Junho 2014): 61-74.

Shell, A. Catholicism, Controversy and the English Literary Imagination, 1558-1660. 


\section{ESTUDOS/ESSAYS}

Cambridge: Cambridge University Press, 2006.

---. Oral Culture and Catholicism in Early Modern England. Cambridge: Cambridge University Press, 2007.

Silva, Maria Teresa Lopes da. Transição de Macau para a Modernidade 1841-1853: Ferreira do Amaral e a Construção da Soberania Portuguesa. Lisboa: Fundação Oriente, 2002.

The Spectator 748, 29-10-1842.

Tiffany, Osmond. The Canton Chinese. Boston: James Monroe, 1849.

Tojal, Altino do. Histórias de Macau. Porto: Campo das Letras, 1998.

Wagner, Tamara, S. "Sketching China and the Self-Portrait of a Post-Romantic Traveler." A Century of Travels in China: Critical Essays on Travel Writing. Hong Kong: Hong Kong University Press, 2007. 13-26.

Watts, Ian E. "Bi-Racial Identity, Bi-Racial Status: Two Chinese Orphans Raised by the Canossian Sisters in Macao". Review of Culture 31 (Abril-Junho de 199): 71-88. 